\title{
Phenolic Profiling of Portuguese Propolis by LC-MS Spectrometry: Uncommon Propolis Rich in Flavonoid Glycosides
}

\author{
Soraia I. Falcão, ${ }^{\text {a,b }}$ Nuno Vale, ${ }^{c}$ Paula Gomes, ${ }^{c}$ Maria R. M. Domingues, ${ }^{d}$ \\ Cristina Freire, ${ }^{b}$ Susana M. Cardoso ${ }^{\mathrm{e}}$ and Miguel Vilas-Boas ${ }^{\mathrm{a} *}$
}

\begin{abstract}
:
Introduction - Propolis is a chemically complex resinous substance collected by honeybees (Apis mellifera) from tree buds, comprising plant exudates, secreted substances from bee metabolism, pollen and waxes. Its chemical composition depends strongly on the plant sources available around the beehive, which have a direct impact in the quality and bioactivity of the propolis. Being as Portugal is a country of botanical diversity, the phenolic characterisation of propolis from the different regions is a priority.

Objective - Extensive characterisation of the phenolic composition of Portuguese propolis from different continental regions and islands.

Method - Forty propolis ethanolic extracts were analysed extensively by liquid chromatography with diode-array detection coupled to electrospray ionisation tandem mass spectrometry (LC-DAD-ESI-MS ${ }^{n}$ ).

Results - Seventy-six polyphenols were detected in the samples and two groups of propolis were established: the common temperate propolis, which contained the typical poplar phenolic compounds such as flavonoids and their methylated/ esterified forms, phenylpropanoid acids and their esters, and an uncommon propolis type with an unusual composition in quercetin and kaempferol glycosides - some of them never described in propolis.

Conclusion - The method allowed the establishment of the phenolic profile of Portuguese propolis from different geographical locations, and the possibility to use some phenolic compounds, such as kaempferol-dimethylether, as geographical markers. Data suggest that other botanical species in addition to poplar trees can be important sources of resins for Portuguese propolis. Copyright $\odot 2012$ John Wiley \& Sons, Ltd.
\end{abstract}

Keywords: Mass spectrometry; flavonoid glycosides; flavonoids; phenolic compounds; propolis

\section{Introduction}

Amongst all bee products, propolis is one of the most complex and, at the same time, very fascinating. Propolis is the name given to an extremely sticky, resinous substance, collected from various floral sources, transformed and used by the honeybees (Apis mellifera L.) to seal holes in their honeycombs, smooth out the internal walls and protect the entrance against intruders. The origin of the word propolis comes from the Greek: prostanding for 'in defense', and polis- meaning 'the city', that is, defense of the city (or the hive) (Burdock, 1998).

Propolis acts as a strong biocide within the hive, being responsible for the low incidence of bacteria and fungi (Marcucci, 1995). This bee product has been widely used in folk medicine since ancient times and recently has gained popularity all over the world as an important ingredient of healthy foods and cosmetics. Propolis is thought to improve human health and to prevent diseases such as inflammation, heart disease, diabetes and even cancer (Banskota et al., 2001).

Frequently referred to as 'bee glue', it is mainly composed of resin (phenolic compounds) but also contains significant amounts of vegetable balsam, wax, essential oils and pollen. Other organic compounds such as amino acids, vitamins, mineral salts and insoluble debris are found as residual components (Marcucci, 1995; Burdock, 1998). The variability of propolis chemical composition is strongly dependent on the plant sources available around the hive and on the geographical and climatic conditions, although bees show a preference for specific resin sources (Bankova et al., 2000). In Europe, North America and other temperate zones the main resin sources are the exudates of apical buds of Populus species, in particular those from Populus nigra (Marcucci, 1995). Propolis from these regions shows similar phenolic composition, with the main compounds being flavonoids (pinocembrin,

* Correspondence to: M. Vilas-Boas, CIMO/Escola Superior Agrária, Instituto Politécnico de Bragança, Campus de Sta. Apolónia, Apartado 1172, 5301-855 Bragança, Portugal. Email: mvboas@ipb.pt

a CIMO/Escola Superior Agrária, Instituto Politécnico de Bragança, Campus de Sta. Apolónia, Apartado 1172, 5301-855 Bragança, Portugal

b REQUIMTE/Departamento de Química e Bioquímica, Faculdade de Ciências da Universidade do Porto, Rua do Campo Alegre, 4169-007 Porto, Portugal

c CIQUP/ Departamento de Química e Bioquímica, Faculdade de Ciências da Universidade do Porto, Rua do Campo Alegre, 4169-007 Porto, Portugal

d Centro de Espectrometria de Massa, Departamento de Química, Universidade de Aveiro, 3810-193 Aveiro, Portugal

e CERNAS/Escola Superior Agrária, Instituto Politécnico de Coimbra, Bencanta, 3040-316 Coimbra, Portugal 
pinobanksin, chrysin and galangin), phenolic acids and their esters (Bankova et al., 2000; Falcão et al., 2010). Different phenolic profiles were found in propolis from Canary Islands, in which furofuran lignans were the main compounds (Bankova et al., 2000). Moreover, terpenes were the major components in propolis from Mediterranean Sea areas, the origin of which was most probably the Cupressaseae family and the species Ferula communis (Popova et al., 2009, 2011). In tropical areas, particularly in Brazil, propolis originating from Baccharis dracunculifolia (green propolis) presented a composition rich in prenylated phenylpropanoids and in caffeoyl quinic acids, whereas propolis from Cuba, Venezuela and some areas in Brazil, arising from flowers of Clusia spp., were shown to be rich in prenylated benzophenone derivatives (Bankova et al., 2000). Chen et al. (2003) have also identified a new family of compounds in propolis samples from Taiwan, the C-prenylflavonoids (or propolins).

In recent years, different analytical approaches have been used for phenolic characterisation of propolis from all over the world (Bankova et al., 2002; Popova et al., 2004; Watson et al., 2006) and of these, the most common technique of choice by far is liquid chromatography coupled with mass spectrometry (LC-MS) (Volpi and Bergonzini, 2006; Gardana et al., 2007; Falcão et al., 2010; Pellati et al., 2011). LC-MS is a powerful tool for the analysis of natural products. The high sensitivity of the MS analytical approach provides the potential for discovery of new minor constituents, which are difficult to obtain by conventional means. More detailed structural information can be obtained by resorting to tandem mass spectrometry (MS/MS), which allows the characterisation of unknown compounds even without reference to standards (Cuyckens and Claeys, 2004).

In our previous work (Falcão et al., 2010), the phenolic compounds of northeast Portuguese propolis were studied by the combined off-line analysis of HPLC and electrospray ionisation (ESI) MS in the negative ion mode. This approach allowed the characterisation of 37 phenolic compounds, which included the typical phenolic acids and flavonoids found in propolis from temperate zones, but also new methylated, esterified and/or hydroxylated derivatives of common poplar flavonoids and pinocembrin/pinobanksin derivatives containing a phenylpropanoic acid derivative moiety in their structure.

More recent works on Portuguese propolis from other regions of Portugal (Miguel et al., 2010; unpublished results) revealed, however, the presence of propolis diversity, observed through differences in the physicochemical parameters and in total phenolic content. This is consistent with the botanical diversity of the country, and the need that bees have for search alternative resin sources in regions where poplar is not present. Our recent work in the study of propolis from distinct Portuguese continental regions and islands clearly identified the existence of different types of propolis, based on the distinct profile of physicochemical parameters identified (unpublished results). The phenolic characterisation of propolis from the different regions is therefore a priority.

In this article we present the results of an extensive study on the phenolic profile of distinct Portuguese continental regions and islands, performed by liquid chromatography with diode-array detection coupled to electrospray ionisation tandem mass spectrometry (LC-DAD-ESI-MS ${ }^{n}$ ), in an attempt to establish the Portuguese propolis phenolic profile. A propolis type with an unusual composition of flavonoid glycosides is described herein.

\section{Experimental}

\section{Chemicals and reagents}

Chrysin, galangin, quercetin, pinocembrin, naringenin, hesperetin, ellagic acid, benzoic acid, cinnamic acid, caffeic acid, ferulic acid, isoferulic acid, p-coumaric acid, caffeic acid isoprenyl ester, caffeic acid phenylethyl ester (CAPE) and quercetin-3-O-rhamnoside were purchased from Sigma Chemical Inc. (St Louis, MO, USA). Apigenin, acacetin, kaempferol, chrysoeriol, chrysin-7-methylether, chrysin-5,7-dimethyl ether, pinocembrin-7-methyl ether, pinocembrin-5,7-dimethyl ether, 3,4-dimethyl-caffeic acid, quercetin-3-O-glucoside, quercetin-3-O-rutinoside, kaempferol-3-Oglucoside, kaempferol-3-O-rutinoside, kaempferol-3-O-neohesperidoside, isorhamnetin-3-O-rutinoside and luteolin-7-O-glucoside were from Extrasynthese (Genay, France). Isorhamnetin and $p$-coumaric acid methyl ether were from Phytolab (Vestenbergsgreuth, Germany). Genkwanin and luteolin were obtained from Lancaster Synthesis (Morecambe, England). Analytical grade formic acid and HPLC grade ethanol were obtained from Panreac (Barcelona, Spain). HPLC-grade methanol and acetonitrile were purchased from Lab-Scan (Lisbon, Portugal). Water was treated in a Milli-Q water purification system (Topway Global Inc.,Houston, TX, USA).

\section{Propolis samples}

This work was performed with 40 Portuguese propolis samples. As shown in Fig. 1, the samples were collected from continental north $(\mathrm{N})$, central interior $(\mathrm{Cl})$, central coast $(\mathrm{CC})$, south $(\mathrm{S})$, Azores archipelago $(\mathrm{A})$ and from Madeira island (M). Table 1 shows the general status of propolis samples, the year of collection and geographical sites, as well as the corresponding collection method. All the samples were obtained after the honey harvesting season (July-September), by conventional scraping or through plastic screens. These propolis samples were then stored at $-20^{\circ} \mathrm{C}$ until analysis.

\section{Phenolic compounds extraction}

The extraction procedure was made according to our previously work (Falcão et al., 2010). The raw propolis samples (1 g) were first grounded,

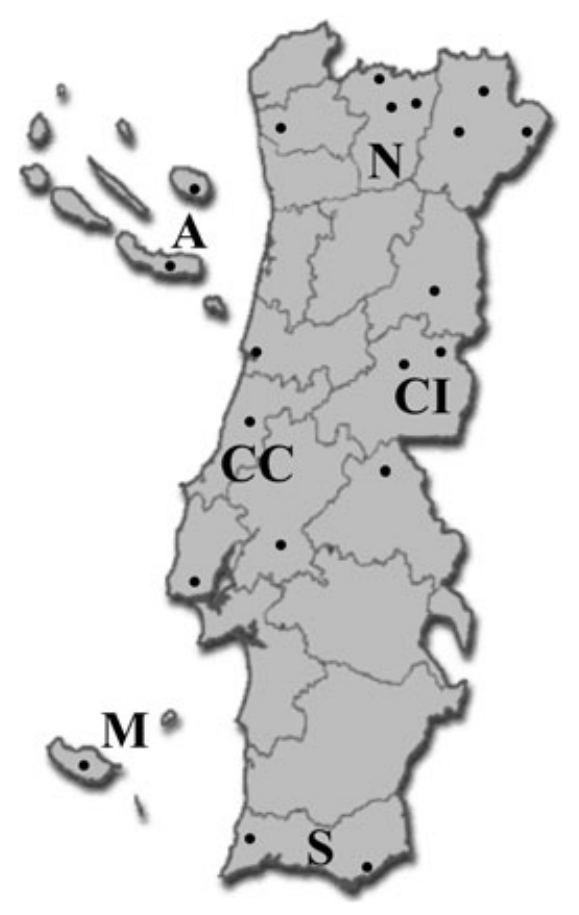

Figure 1. Propolis sampling sites. 
Table 1. Propolis samples description

\begin{tabular}{|c|c|c|c|c|}
\hline Code & Geographical location & Year & Collection method $^{\mathrm{a}}$ & Propolis type \\
\hline N1 & Bragança & 2007 & 1 & Common \\
\hline N2 & Bragança & 2007 & 2 & Common \\
\hline N3 & Bragança & 2008 & 2 & Common \\
\hline N4 & Bragança & 2009 & 1 & Common \\
\hline N5 & Bragança & 2009 & 1 & Common \\
\hline N6 & Bragança & 2009 & 1 & Common \\
\hline N7 & Miranda do Douro & 2009 & 1 & Common \\
\hline N8 & Mirandela & 2009 & 2 & Common \\
\hline N9 & Chaves & 2009 & 2 & Common \\
\hline N10 & Chaves & 2009 & 2 & Common \\
\hline N11 & Montalegre & 2009 & 1 & Uncommon \\
\hline N12 & Boticas & 2009 & 1 & Uncommon \\
\hline N13 & Boticas & 2009 & 1 & Uncommon \\
\hline N14 & Barcelos & 2010 & 1 & Common \\
\hline $\mathrm{Cl} 1$ & Guarda & 2009 & 1 & Uncommon \\
\hline $\mathrm{Cl} 2$ & Penamacor & 2009 & 1 & Common \\
\hline $\mathrm{Cl} 3$ & Fundão & 2009 & 1 & Common \\
\hline $\mathrm{Cl} 4$ & Nisa & 2009 & 2 & Common \\
\hline $\mathrm{CC} 1$ & Figueira da Foz & 2009 & 2 & Common \\
\hline CC2 & Leiria & 2009 & 1 & Common \\
\hline $\mathrm{CC} 3$ & Coruche & 2009 & 2 & Common \\
\hline CC4 & Ramada & 2009 & 1 & Common \\
\hline S1 & Aljezur & 2009 & 1 & Common \\
\hline $\mathrm{S} 2$ & Aljezur & 2009 & 1 & Common \\
\hline S3 & Aljezur & 2009 & 1 & Common \\
\hline S4 & Moncarapacho & 2009 & 1 & Uncommon \\
\hline $\mathrm{A} 1$ & Terceira Island, Azores Archipelago & 2009 & 1 & Common \\
\hline $\mathrm{A} 2$ & S. Miguel Island, Azores Archipelago & 2009 & 1 & Common \\
\hline A3 & S. Miguel Island, Azores Archipelago & 2009 & 1 & Common \\
\hline A4 & S. Miguel Island, Azores Archipelago & 2009 & 1 & Common \\
\hline A5 & S. Miguel Island, Azores Archipelago & 2009 & 1 & Common \\
\hline A6 & S. Miguel Island, Azores Archipelago & 2009 & 1 & Common \\
\hline A7 & S. Miguel Island, Azores Archipelago & 2009 & 1 & Common \\
\hline A8 & S. Miguel Island, Azores Archipelago & 2009 & 1 & Common \\
\hline A9 & S. Miguel Island, Azores Archipelago & 2009 & 1 & Common \\
\hline A10 & S. Miguel Island, Azores Archipelago & 2009 & 1 & Common \\
\hline A11 & S. Miguel Island, Azores Archipelago & 2009 & 1 & Common \\
\hline M1 & Funchal, Madeira Island & 2009 & 1 & Common \\
\hline M2 & Funchal, Madeira Island & 2009 & 1 & Uncommon \\
\hline M3 & Funchal, Madeira Island & 2009 & 1 & Common \\
\hline
\end{tabular}

homogenised and then mixed with $80 \%$ ethanol $(10 \mathrm{~mL})$ and kept at $70^{\circ} \mathrm{C}$ for $1 \mathrm{~h}$. The resulting mixture was filtered and the residue was re-extracted in the same conditions. After the second extraction, the filtered solution was combined, concentrated, frozen at $-20^{\circ} \mathrm{C}$ and freeze-dried.

\section{LC-DAD-ESI-MS ${ }^{n}$ analysis}

The LC-DAD-ESI-MS ${ }^{n}$ analyses were performed on a Finnigan Surveyor Plus HPLC instrument equipped with a DAD and coupled to a MS. The chromatographic system consisted of a quaternary pump, an autosampler, a degasser, a photodiode-array detector and an automatic thermostatic column compartment. The HPLC was run on a Macherey-Nagel Nucleosil $\mathrm{C}_{18}$-column $(250 \mathrm{~mm} \times 4 \mathrm{~mm}$ i.d.; $5 \mu \mathrm{m}$ particle diameter, end-capped) and its temperature was maintained at $25^{\circ} \mathrm{C}$. The mobile phase was composed of (A) $0.1 \%$ (v/v) formic acid in water, and (B) acetonitrile, which were previously degassed and filtered. The solvent gradient started with $80 \% \mathrm{~A}$ and $20 \% \mathrm{~B}$, reaching $30 \% \mathrm{~B}$ at $10 \mathrm{~min}, 40 \% \mathrm{~B}$ at $40 \mathrm{~min}, 60 \% \mathrm{~B}$ at $60 \mathrm{~min}, 90 \% \mathrm{~B}$ at $80 \mathrm{~min}$ and return to the initial conditions. For the HPLC analysis, the freeze-dried extract $(10 \mathrm{mg})$ was dissolved in $1 \mathrm{~mL}$ of $80 \%$ of ethanol. All samples were filtered through a $0.2 \mu \mathrm{m}$ Nylon membrane (Whatman). The flow rate was $1 \mathrm{~mL} / \mathrm{min}$ and split out $200 \mu \mathrm{L} / \mathrm{min}$ to $\mathrm{MS}$. Spectral data for all peaks were acquired in the range $200-600 \mathrm{~nm}$.

The MS used was a Finnigan Surveyor LCQ XP MAX quadrupole ion trap MS equipped with an ESI source. Control and data acquisition were carried out with the Xcalibur ${ }^{\circledR}$ data system (ThermoFinnigan, San Jose, CA, USA). Nitrogen above $99 \%$ purity was used and the gas pressure was $520 \mathrm{kPa}$ (75 psi). The instrument was operated in negative-ion mode, with ESI needle voltage set at $5.00 \mathrm{kV}$ and the ESI capillary temperature at $325^{\circ} \mathrm{C}$. The full scan covered 
the mass range from $\mathrm{m} / \mathrm{z} 50$ to 1000 . The $\mathrm{MS}^{n}$ data were simultaneously acquired for the selected precursor ion. The collision induced decomposition (CID)-MS-MS and $M^{n}{ }^{n}$ experiments were performed using helium as the collision gas, with a collision energy of $25-40 \mathrm{eV}$.

\section{Results and discussion}

The LC-DAD-ESI-MS ${ }^{n}$ study of the 40 Portuguese propolis samples allowed the elucidation of phenolic compounds by comparison of their chromatographic behaviour, UV spectra and MS information with reference compounds. When standards were not available, the structural information was confirmed with UV data combined with MS fragmentation patterns previously reported in the literature. This study was carried out using LC-MS in the negative ion mode because of its higher sensitivity in the analysis of the different polyphenol classes (Cuyckens and Claeys, 2004).

Overall, the Portuguese propolis samples could be arranged in two distinct groups (Table 1): (i) common temperate propolis type, which contained, for example, the typical poplar phenolic compounds such as the main phenolic components; and (ii) uncommon temperate propolis type, which in addition to the typical poplar flavonoids, also contained significant amounts of unusual flavonoid glycosides. Figure 2 shows the representative chromatographic profile at $280 \mathrm{~nm}$ for the two types of propolis found. The phenolic composition of the two groups is detailed below.

\section{Common temperate propolis type}

Overall, more than $85 \%$ of the Portuguese propolis samples under study were identified as common temperate propolis with a common phenolic matrix (Falcão et al., 2010). This group included all the samples from the central coast and Azores archipelago, as well as the majority of samples from the north, and some from the central interior, south and Madeira. It is important, nevertheless, to note that some of the samples included in this group showed deviations to the typical phenolic profile of temperate regions. In particular, all samples from the central coast, samples N11-N13 from the north, samples S2-S3 from the south and sample M3 from Madeira contained an additional flavonol, the kaempferide. Moreover, samples $\mathrm{Cl} 2-\mathrm{Cl} 4$ from central interior and S2-S4 (south) were poor in pinobanskin derivatives but contained a kaempferol-dimethyl ether, which is not typically observed in the temperate propolis profile. Sample M1 from Madeira exhibits a small number of phenolic compounds.

In general, the analytical approach used in the present study allowed the identification of 62 compounds in common temperate propolis type samples (Table 2). These included the 37 phenolic compounds previously reported (Falcão et al., 2010) plus (i) 19 new confirmed phenolic compounds $(6,9,11,12,18,19,22-24,26-28$, $36-38,44,47,54,62)$ and (ii) six new compounds $(46,49,55,56$, $59,60)$ for which the structure will be partially elucidated herein.

In addition to our previous results, benzoic acid (molecular weight $(\mathrm{MW}) 122 \mathrm{Da}$ ) has now been detected as a minor peak in all samples (compound 6 at $23.5 \mathrm{~min}$ ), and cinnamic acid ( $m / z$ 147, compound 11) was found in most of the samples. Note
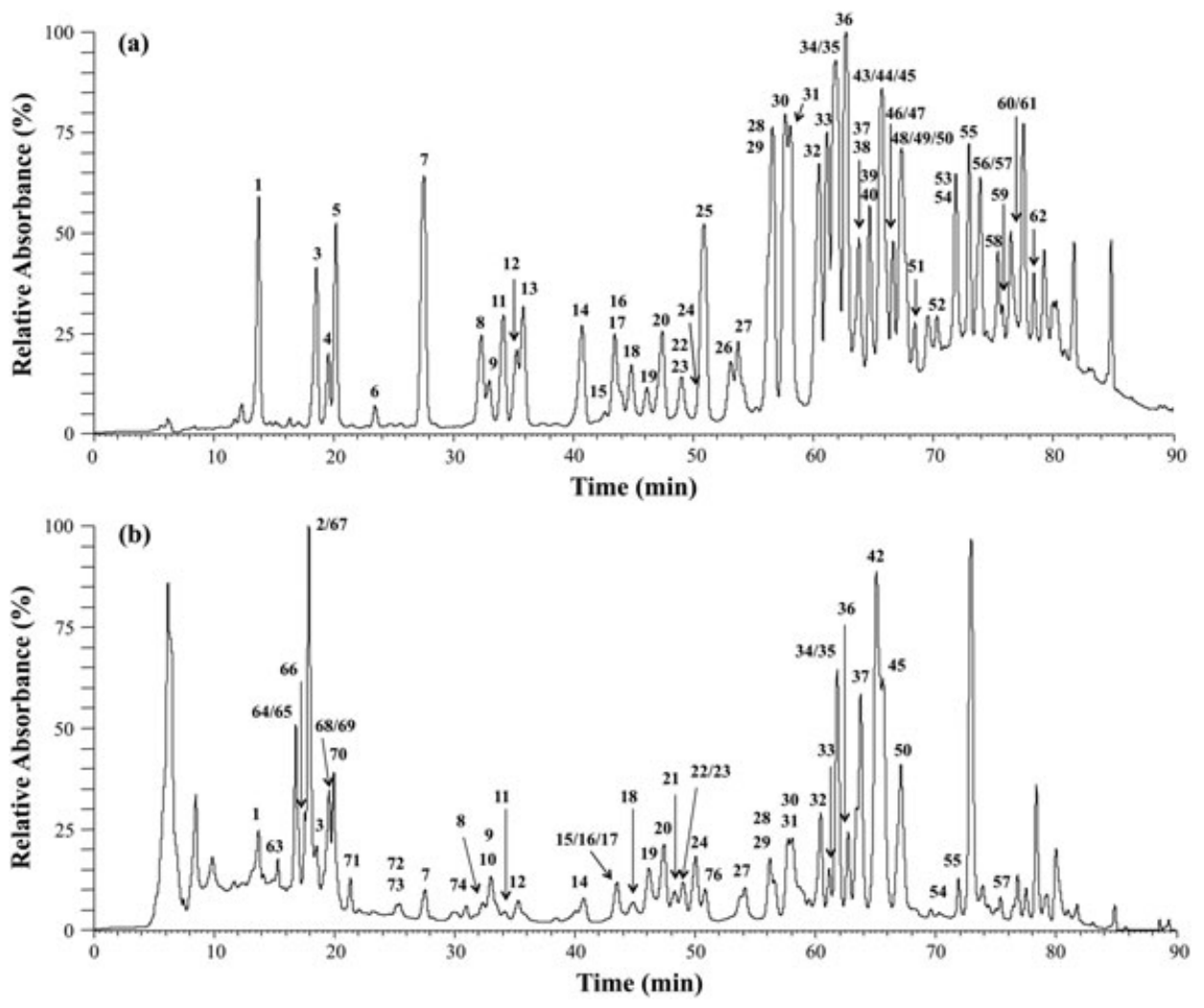

Figure 2. Representative chromatographic profile at $280 \mathrm{~nm}$ of ethanolic propolis extracts: (a) common temperate propolis type; (b) uncommon propolis type. 


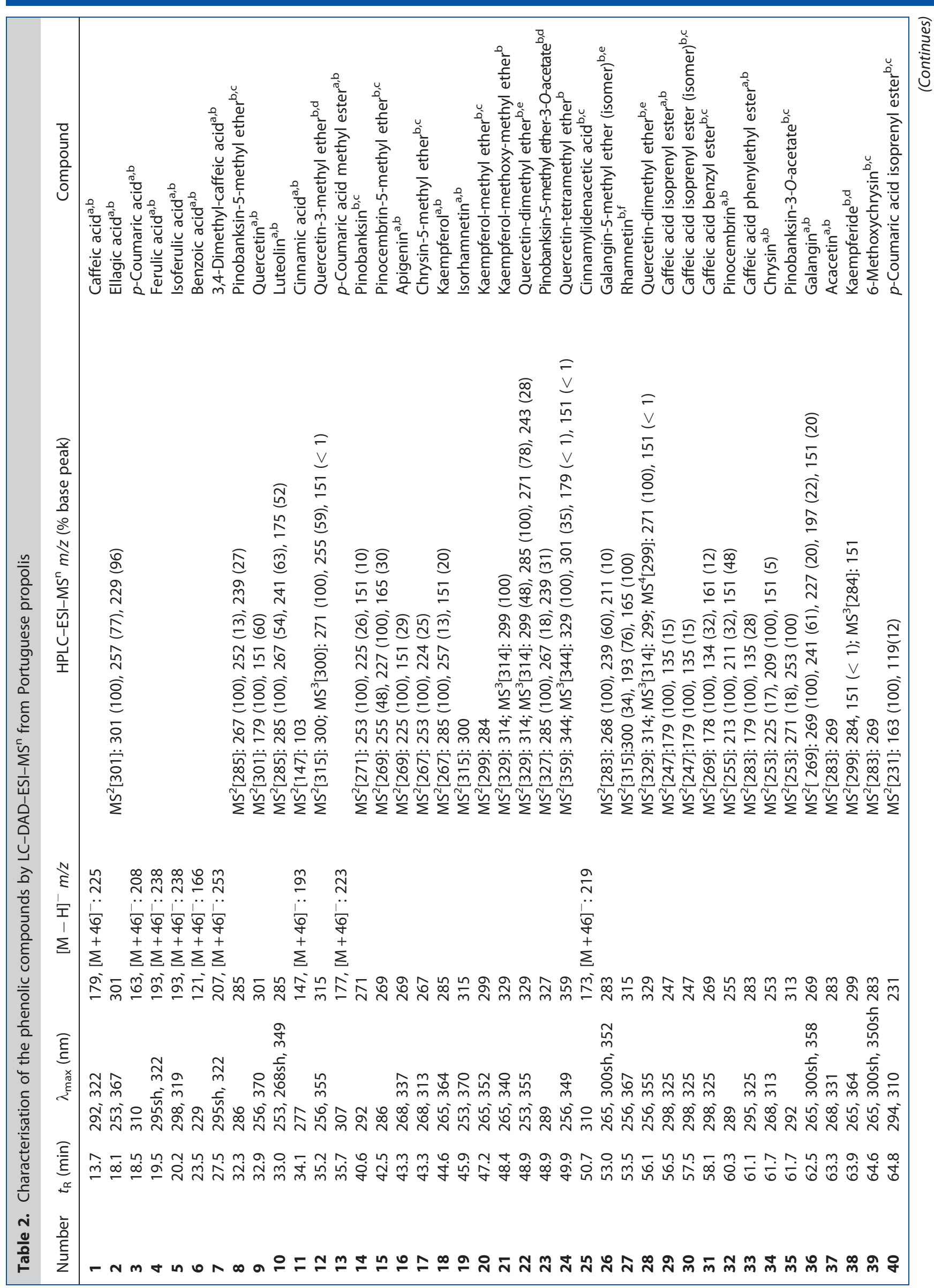



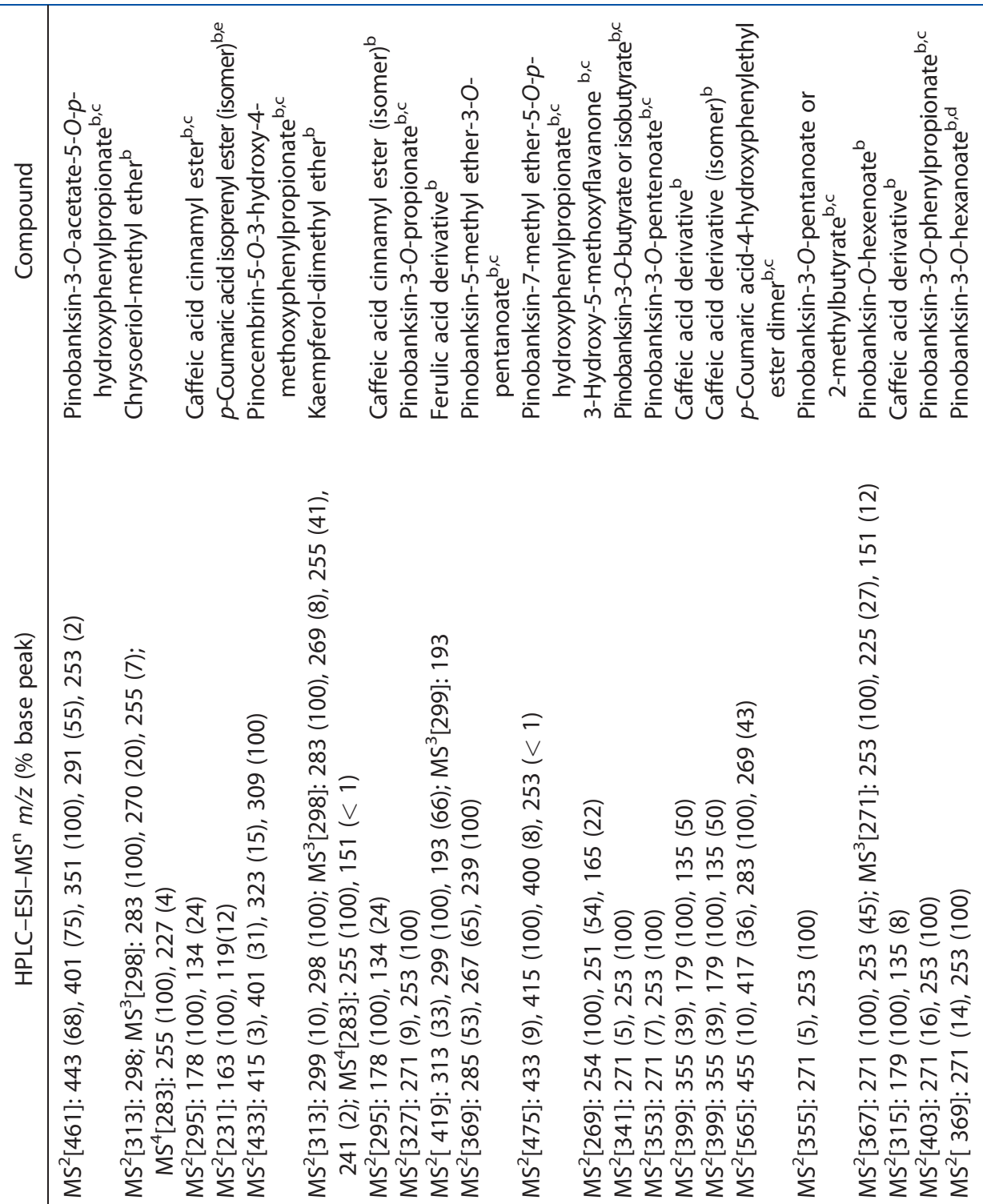

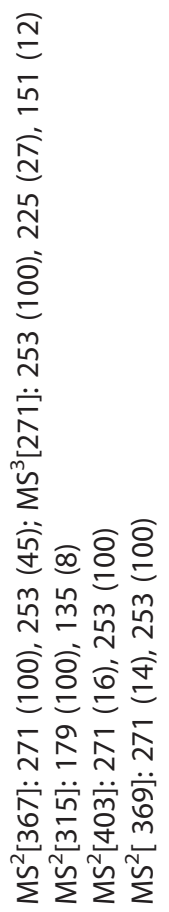

है

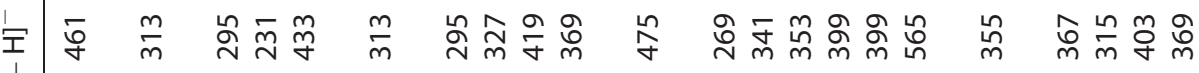

$\sum$

$\underset{m}{\approx} \underset{m}{\approx}$ 每

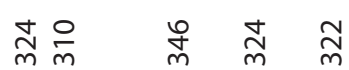

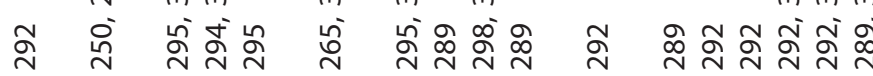

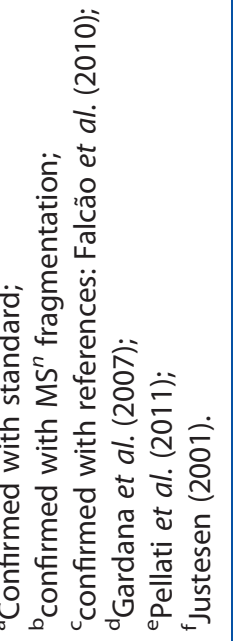


that in this study, these acids (as well as the remaining simple acids in the propolis extracts) were mainly detected in the $\mathrm{LC}-\mathrm{MS}$ both with formation of the $[\mathrm{M}+\mathrm{HCOOH}]^{-}$adduct $\left([\mathrm{M}+46]^{-}\right)$. Formation of an adduct with formic acid was observed previously in the characterisation of this type of phenolic compound (de Rijke et al., 2003). In addition to those two acids, one ferulic acid derivative and three other caffeic acid derivatives were detected in this study. Indeed, although the structure of these compounds was not totally elucidated, it was possible to observe a UV spectrum equivalent to that of caffeic acid $(292,322 \mathrm{~nm})$ in compounds 55, 56 and 60. Moreover, the $\mathrm{MS}^{2}$ spectrum of the $[\mathrm{M}-\mathrm{H}]^{-}$at $\mathrm{m} / \mathrm{z} 399$ (isomeric compounds 55 and 56) showed a base peak ion at $\mathrm{m} / z$ 179, which corresponds to caffeic acid and an ion at $m / z 135$ resulting from the loss of $\mathrm{CO}_{2}$ from the phenolic acid. In a similar manner, the $[\mathrm{M}-\mathrm{H}]^{-}$at $m / z 419$ in compound 49 was assigned to a ferulic acid derivative, as it presented $U_{\text {max }}$ at 298 and $322 \mathrm{~nm}$ and its $M^{3} S^{3}$ spectrum showed an ion at $m / z$ 193, both consistent with ferulic acid.

It is worth noting the large number of methoxylated flavonols in these Portuguese propolis samples, namely quercetin and kaempferol derivatives. These polyphenols were not detected in our previous work due to the methodological approach used, where the major eluted peaks were collected as fractions and directly injected into the ESI source and subsequently analysed (Falcão et al., 2010). These compounds include several monomethyl ether and polymethyl ether quercetin derivatives, namely quercetin-3-methyl ether (12), isorhamnetin (19), quercetin-dimethyl ether (22), quercetin-tetramethyl ether (24), rhamnetin (27) and quercetin-dimethyl ether (28), which previously have been detected as major components of plant exudates, resins and waxes (Stevens et al., 1995). Within the kaempferol derivatives, it was possible to detect kaempferol-methyl ether (20), kaempferide (38) and kaempferol-dimethyl ether (46). Also, galangin-5-methyl ether (26), with a precursor ion at $m / z 283$, was identified in the majority of the propolis samples. A flavone derivative identified as acacetin (37) was also found in samples of Portuguese common temperate propolis type.

Besides the dihydroflavonols already described in Portuguese propolis, pinobanksin-3-O-pentenoate (54) and pinobanksin-3$O$-hexanoate (62) were herein assigned by comparison of their UV spectrum and fragmentation pattern with the reported literature and also with the pinobanksin derivative (59) eluted at $76.2 \mathrm{~min}$. The latter presented an absorption maximum peak at $292 \mathrm{~nm}$, which is consistent with pinobanksin (Gardana et al., 2007). Moreover, its ESI-MS showed a $[\mathrm{M}-\mathrm{H}]^{-}$ion at $\mathrm{m} / \mathrm{z} 367$ (Table 2), and the main product ion $(\mathrm{m} / \mathrm{z} 271)$ in its $\mathrm{MS}^{2}$ spectrum resulted from the loss of a hexenoate group ( $-96 \mathrm{Da}$ ) (Sharkey et al., 1959), suggesting an isomer of pinobanksin-O-hexenoate.

\section{Uncommon propolis type}

Six of the 40 Portuguese propolis samples had a particular phenolic profile different from that of the common temperate propolis samples (Table 1). As shown in Fig. 2, their chromatograms had a group of peaks at early retention times, associated with flavonoid glycosides. Due to their rarity in propolis matrices, we will describe these compounds in detail in the following section. Moreover, these six propolis samples contained four other phenolic compounds that were not detected in the common propolis samples (Table 2): ellagic acid (2), luteolin (10), a dimethoxylated flavonol (21) and a dihydroxy-dimethoxyflavone (42).
The UV spectrum of the dimethoxylated flavonol peak was equivalent to that of kaempferol and its full MS spectrum had a $[\mathrm{M}-\mathrm{H}]^{-}$at $\mathrm{m} / \mathrm{z}$ 329. Moreover, $\mathrm{MS}^{2}$ and $\mathrm{MS}^{3}$ experiments indicated the successive loss of methyl groups $(-15 \mathrm{Da})$, with the formation of the product ions at $\mathrm{m} / \mathrm{z} 314$ and $\mathrm{m} / \mathrm{z} 299$, respectively. Overall, the data pointed to the presence of kaempferol-methoxymethyl ether with the methoxy group linked to the C-6 position, as previously described (Kumazawa et al., 2003).

Experimental data of the dihydroxy-dimethoxyflavone (42) suggested the presence of chrysoeriol-methyl ether. In fact, its UV spectrum was equivalent to that of chrysoeriol $(250,268 \mathrm{sh}$ and $343 \mathrm{~nm})$ and the $\mathrm{MS}^{2}$ spectrum of the molecular ion $(\mathrm{m} / \mathrm{z}$ 313) showed a loss of a methyl group, which resulted in the formation of a base peak product ion $(\mathrm{m} / \mathrm{z} 298)$, the latter with a similar fragmentation pattern to that of chrysoeriol.

\section{Flavonoid glycosides}

As previously mentioned, uncommon propolis type samples typically contained flavonoid glycosides in their composition. We must highlight that phenolic glycosides are rare in propolis because of the hydrophobic nature of plant sources of the resin and due to the presence of $\beta$-glucosidase enzymes during propolis collection and processing. This last point has been under debate, as recent studies (Zhang et al., 2011) demonstrated the inefficiency of the enzyme to hydrolyse $\beta$-diglycosides. Also, Bankova et al. (2000) suggested the possibility of no chemical changes in plant material during propolis collection. Anyway, to our knowledge, the only flavonoids glycosides previously reported in propolis matrices were the isorhamnetin-3-O-rutinoside, isolated from Cretan propolis (Popova et al., 2009), and rutin (quercetin 3-O-rutinoside), which has been identified in European, Asian and South American propolis (Bonvehí and Call, 1994).

The LC-DAD-ESI-MS ${ }^{n}$ data of the 14 flavonoid glycosides of the uncommon propolis type samples showed that these were quercetin and kaempferol derivatives. In this study, five of those compounds were identified by comparison of UV and LC-MS data with those of the corresponding reference product: quercetin-3-O-rutinoside (63), quercetin-3-O-glucoside (65), kaempferol-3-O-rutinoside (66), isorhamnetin-3-O-rutinoside (67) and quercetin-3-O-rhamnoside (69). The structure of the nine remaining compounds was assigned based on their UV spectra and interpretation of their fragmentation pathways observed in $\mathrm{MS}^{n}$ spectra, as will be discussed in detail. Sugar moieties in flavonoids were assigned to glucosides, rutinosides and glucuronides, because these are most common and frequent in nature and are now confirmed in propolis, although the presence of galactoside moieties seems also consistent, particularly due to its resistance to bee enzymes hydrolysis. Note that the glycosylation position of these polyphenols will not be ascribed in the present work, but these are commonly C-3 or C-7 (Santos-Buelga et al., 2003). Representative structures of the flavonoids glycosides found in the uncommon temperate propolis type samples are shown in Fig. 3, where the most probable linkage positions are considered. Thus, the structures proposed in Fig. 3 should be regarded only as an example.

Seven of those compounds, 64, 68, 70 and 72-75, corresponded to quercetin glycosides. The UV spectrum of compound 64 (similar to that of quercetin) and the identification of the $[\mathrm{M}-\mathrm{H}]^{-}$ion at $\mathrm{m} / \mathrm{z} 477$ in the corresponding MS spectrum suggest that the 


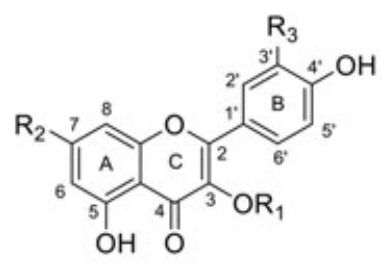

\begin{tabular}{|c|c|c|c|c|}
\hline Compound & Name & $\mathbf{R}_{1}$ & $\mathbf{R}_{2}$ & $\mathbf{R}_{3}$ \\
\hline 63 & Quercetin-3-O-rutinoside & Rut & $\mathrm{OH}$ & $\mathrm{OH}$ \\
\hline 64 & Quercetin-3-O-glucuronide & GlcUA & $\mathrm{OH}$ & $\mathrm{OH}$ \\
\hline 65 & Quercetin-3-O-glucoside & Glc & $\mathrm{OH}$ & $\mathrm{OH}$ \\
\hline 66 & Kaempferol-3- $O$-rutinoside & Rut & $\mathrm{OH}$ & $\mathrm{H}$ \\
\hline 67 & Isorhamnetin-3-O-rutinoside & Rut & $\mathrm{OH}$ & $\mathrm{OCH}_{3}$ \\
\hline 68 & Isorhamnetin- $O$-pentoside & Pent & $\mathrm{OH}$ & $\mathrm{OCH}_{3}$ \\
\hline 69 & Quercetin-3-O-rhamnoside & Rham & $\mathrm{OH}$ & $\mathrm{OH}$ \\
\hline 70 & Isorhamnetin- $O$-glucuronide & GlcUA & $\mathrm{OH}$ & $\mathrm{OCH}_{3}$ \\
\hline 71 & Kaempferol-methyl-ether- $O$-glucoside & Gle & $\mathrm{OCH}_{3}$ & $\mathrm{H}$ \\
\hline 72 & Isorhamnetin- $O$-acetylrutinoside & Rut-Ac & $\mathrm{OH}$ & $\mathrm{OCH}_{3}$ \\
\hline 73 & Rhamnetin- $O$-glucuronide & GlcUA & $\mathrm{OCH}_{3}$ & $\mathrm{OH}$ \\
\hline 74 & Quercetin-dimethyl-ether- $O$-rutinoside & Rut & $\mathrm{OCH}_{3}$ & $\mathrm{OCH}_{3}$ \\
\hline 75 & Quercetin-dimethyl-ether- $O$-glucuronide & GlcUA & $\mathrm{OCH}_{3}$ & $\mathrm{OCH}_{3}$ \\
\hline 76 & Kaempferol-O-p-coumaroylrhamnoside & Rham-Coum & $\mathrm{OH}$ & $\mathrm{H}$ \\
\hline
\end{tabular}

Figure 3. Proposed structures for the flavonoid glycosides identified in Portuguese propolis.

compound with a MW of $478 \mathrm{Da}$ is a glucuronic derivative of quercetin. In fact, the product ion at $\mathrm{m} / \mathrm{z} 301$ (quercetin) was formed by the loss of $176 \mathrm{Da}$, which is indicative of a glucuronyl unit (Cuyckens and Claeys, 2004). In addition to the aglycone fragment, the $\mathrm{MS}^{2}$ spectrum of this quercetin-O-glucuronide also showed a major product ion at $m / z 300$, formed by the homolytic cleavage of the $O$-glycosidic bond, and has been proposed as indicative of quercetin glycosides (Constant et al., 1997). The ion at $\mathrm{m} / \mathrm{z} 300$ was also observed in the $\mathrm{MS}^{2}$ spectrum of the remaining quercetin glycosides. Compounds 68, 70 and 72-75 were identified as methylated derivatives of quercetin glycosides, and all presented a UV spectrum equivalent to that of isorhamnetin3-O-rutinoside (Table 3). Compound 68 showed an ESI-MS ${ }^{2}$ spectrum with a base peak ion at $\mathrm{m} / \mathrm{z} 315(-132 \mathrm{Da})$ and the fragmentation pattern of the latter ion corresponded to that of isorhamnetin. Thus, overall, the data indicated that the phenolic compound eluting at 19.6 min corresponded to an isorhamnetin pentoside derivative. Most probably, the pentoside residue moiety could be assigned to xylose or arabinose, because these two are the most commonly found in polyphenols (Cuyckens and Claeys, 2004). On the other hand, both compounds 70 and 73 presented a $[\mathrm{M}-\mathrm{H}]^{-}$ion at $\mathrm{m} / \mathrm{z} 491$ and the base peak in the $\mathrm{MS}^{2}$ spectrum $(\mathrm{m} / \mathrm{z} 315)$ was formed due to the loss of a glucuronide residue $(-176 \mathrm{Da})$. Moreover, the fragmentation pathway (observed in the $\mathrm{MS}^{3}$ spectrum) of the ion at $\mathrm{m} / \mathrm{z} 315$ in compound 70 was equivalent to that of isorhamnetin (methyl group in C-3' position), whereas that of compound 73 was equivalent to that of rhamnetin (methyl group in C-7 position). In accordance with these results, compounds 70 and 73 (MW $492 \mathrm{Da}$ ) were respectively assigned to isorhamnetin-O-glucuronide and rhamnetin-O-glucuronide. The MS analysis of compound 72 showed the $[\mathrm{M}-\mathrm{H}]^{-}$at $\mathrm{m} / \mathrm{z}$ 665 , and the $M S^{2}$ spectrum showed a main product ion at $\mathrm{m} / \mathrm{z}$ 315 ( $-350 \mathrm{Da}$, a combined loss of rutinose and one acetyl residue), which corresponded to isorhamnetin, and an ion at $\mathrm{m} / \mathrm{z} 623$ ( $-42 \mathrm{Da}$, loss of acetyl group). Both these product ions are coherent with the presence of an acetyl disaccharide moiety in the molecule. Note that flavonoid glycosides with an acylated glycosyl moiety part can be identified by the presence, in their $\mathrm{MS}^{2}$ spectra, of the product ions [acylsugar $-\mathrm{H}]^{-}$and $\left[\mathrm{M}-\mathrm{H}-\right.$ acyl] ${ }^{-}$ (Parejo et al., 2004), which are reported here. Thus, the data discussed led us to propose compound 72 as isorhamnetin$O$-acetylrutinoside. The linkage positions of the acyl group on the glycosidic part of the molecule and that of the acylsugar group on the aglycone could not be established on the basis of the UV spectra or on the MS data, as also found in the literature (Parejo et al., 2004). Compounds 74 and 75 showed a similar base peak ion in their ESI-MS ${ }^{2}$ spectrum $(\mathrm{m} / \mathrm{z}$ 329) (Table 3$)$ that was obtained by the loss of a rutinoside $(-308 \mathrm{Da})$ and a glucuronide unit (-176), respectively. Furthermore, as the fragmentation pattern of that ion $(\mathrm{m} / \mathrm{z}$ 329) was consistent with that described earlier for quercetin-dimethyl ether, we propose to assign compounds 74 and 75 to quercetin-dimethyl ether-O-rutinoside and quercetin-dimethyl ether-O-glucuronide, respectively.

Kaempferol glycosides were present in compounds $71(\mathrm{~m} / \mathrm{z} 461)$ and $76\left(\mathrm{~m} / \mathrm{z}\right.$ 577). In the first case, the $\mathrm{MS}^{2}$ data of the ion $[\mathrm{M}-\mathrm{H}]^{-}$ at $\mathrm{m} / \mathrm{z} 461$ was consistent with kaempferol-methyl ether-Ohexoside: it showed a product ion at $\mathrm{m} / \mathrm{z} 446(-15 \mathrm{Da})$ and a base peak product ion at $\mathrm{m} / \mathrm{z} 299$ (-162 Da, loss of a hexoside, most probably glucose). For compound 76 the ESI-MS ${ }^{2}$ data obtained for its $[\mathrm{M}-\mathrm{H}]^{-}$ion at $\mathrm{m} / \mathrm{z} 577$ presented a base peak product ion at $\mathrm{m} / \mathrm{z} 285$ with a fragmentation pattern similar to that of kaempferol, and a mass loss of 146 and 292 Da. The elution time for this compound is significantly greater than all the other flavonoid glycosides and the UV spectrum shape shows deviations from the flavonoid derivatives, with maxima at 265 and $319 \mathrm{~nm}$ (data not shown), where the band I is shifted to lower wavelengths with an increase in intensity. This UV behaviour was observed when an acylation by an aromatic acid occurs (Santos-Buelga et al., 2003). The results for this compound are consistent with a kaempferol linked with an acylated glycoside, most probably a $p$-coumaroylrhamnose (Santos-Buelga et al., 2003; Cuyckens and Claeys, 2004), however, further structural studies by NMR are necessary to determine the precise location of the groups in the flavonoid. 


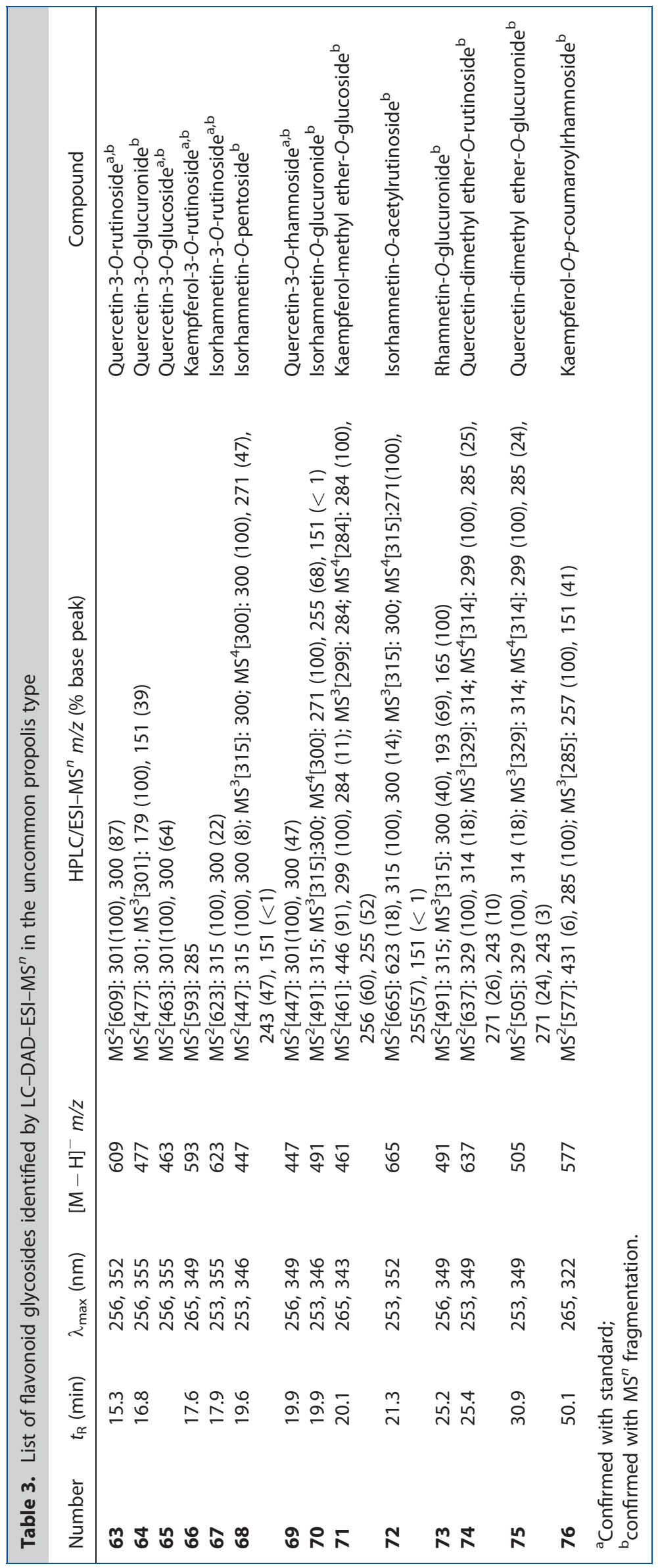




\section{Summary}

Overall, LC-MS data analysis of glycoside propolis type samples suggest the existence of one or more plant sources of propolis resin around the respective apiary, in addition to Populus species. The diversity of resin sources available for honeybees makes the identification of the exact botanical origin of the flavonoid glycosides found in those propolis samples difficult. As these collection regions are rich in conifer plants, however, it is possible that these can be the main source of the glycoside flavonoids (Popova et al., 2009) described herein.

\section{Acknowledgements}

Soraia I. Falcão thanks FCT for the PhD grant SFRH/BD/44855/ 2008. N. Vale thanks FCT for the Post-doctorate grant SFRH/ BPD/48345/2008. Thanks also to FCT for financial support provided to CERNAS (project PEst-OE/AGR/UI0681/2011), to QOPNA (project PEst-C/QUI/UI0062/2011), to CIMO (PEst-OE/ AGR/UI0690/2011) and to the CIQUP LC-MS facility through project CONC-REEQ/275/QUI. Thanks to the National Federation of Portuguese Beekeepers for the propolis samples.

\section{REFERENCES}

Bankova VS, De Castro SL, Marcucci MC. 2000. Propolis: recent advances in chemistry and plant origin. Apidologie 31: 3-15.

Bankova V, Popova M, Bogdanov S, Sabatini AG. 2002. Chemical composition of european propolis: expected and unexpected results. Z Naturforsch 57c: 530-533.

Banskota AH, Tezuka Y, Kadota SH. 2001. Recent progress in pharmacological research of propolis. Phytother Res 15: 561-571.

Bonvehí JS, Call FV. 1994. Phenolic composition of propolis from China and from South America. Z Naturforsch 49c: 712-18.

Burdock GA. 1998. Review of the biological properties and toxicity of bee propolis (propolis). Food Chem Toxicol 36: 347-363.

Chen Ch, Wu Chi, Shy H, Lin J. 2003. Cytotoxic prenylflavanones from Taiwanese propolis. J Nat Prod 66: 503-506.

Constant HL, Slowing K, Graham JG, Pezzuto JM, Cordell GA, Beecher CWW. 1997. A general method for the dereplication of flavonoid glycosides utilizing high performance liquid chromatography/mass spectrometry analysis. Phytochem Anal 8: 176-180.

Cuyckens F, Claeys M. 2004. Mass spectrometry in the structural analysis of flavonoids. J Mass Spectrom 39: 1-15.

De Rijke E, Zappey H, Ariese F, Gooijer C, Brinkman UAT. 2003. Liquid chromatography with atmospheric pressure chemical ionization and electrospray ionization mass spectrometry of flavonoids with triplequadrupole and ion-trap instruments. J Chromatogr A 984: 45-58.

Falcão S, Vilas-Boas M, Estevinho LM, Barros C, Domingues MRM, Cardoso SM. 2010. Phenolic characterization of northeast Portuguese propolis: usual and unusual compounds. Anal Bioanal Chem 396: 887-897.
Gardana C, Scaglianti M, Pietta P, Simonetti P. 2007. Analysis of the polyphenolic fraction of propolis from different sources by liquid chromatography tandem mass spectrometry. J Pharm Biomed Anal 45: 390-399.

Justesen U. 2001. Collision-induced fragmentation of deprotonated methoxylated flavonoids, obtained by electrospray ionization mass spectrometry. J Mass Spectrom 36: 169-178.

Kumazawa S, Yoneda M, Shibata I, Kanaeda J, Hamasaka T, Nakayama T. 2003. Direct evidence for the plant origin of Brazilian propolis by the observation of honeybee behavior and phytochemical analysis. Chem Pharm Bull 51: 740-742.

Marcucci MC. 1995. Propolis: Chemical composition, biological properties and therapeutic activity. Apidologie 26: 83-99.

Miguel MG, Nunes S, Dandlen SA, Cavaco AM, Antunes MD. 2010. Phenols and antioxidant activity of hydro-alcoholic extracts of propolis from Algarve, South of Portugal. Food Chem Toxicol 48: 3418-3423.

Parejo I, Jáuregui O, Viladomat F, Bastida J, Codina C. 2004. Characterization of acylated flavonoid-O glycosides and methoxylated flavonoids from Tagetes maxima by liquid chromatography coupled to electrospray ionization tandem mass spectrometry. Rapid Commun Mass Spectrom 18: 2801-2810.

Pellati F, Orlandini G, Pinetti D, Benvenuti S. 2011. HPLC-DAD and HPLCESI-MS/MS methods for metabolite profiling of propolis extracts. $J$ Pharm Biomed Anal 55: 934-948.

Popova M, Bankova V, Butovska D, Petkov V, Nikolova-Damyanova B, Sabatini AG, Marcazzan GL, Bogdanov S. 2004. Validated methods for the quantification of biologically active constituents of poplartype propolis. Phytochem Anal 15: 235-240.

Popova MP, Chinou IB, Marekov IN, Bankova VS. 2009. Terpenes with antimicrobial activity from Cretan propolis. Phytochemistry 70: 1262-1271.

Popova M, Trusheva B, Antonova D, Cutajar S, Mifsud D, Farrugia C, Tsvetkova I, Najdensky H, Bankova V. 2011. The specific chemical profile of Mediterranean propolis from Malta. Food Chem 126: 1431-1435.

Santos-Buelga C, Garcia-Viguera C, Tomás-Barberán FA. 2003. On-line identification of flavonoids by HPLC coupled to diode array detection. In Methods in Polyphenols Analysis, Santos-Buelga C, Williamson G (eds.). The Royal Society of Chemistry: Cambrigde; 93-127.

Sharkey Jr AG, Shultz JL, Friedel RA. 1959. Mass spectra of esters. Anal Chem 31: 87-94.

Stevens JF, Hart HT, Wollenweber E. 1995. The systematic and evolutionary significance of exudates flavonoids in Aeonium. Phytochemistry 39: 805-813.

Volpi N, Bergonzini G. 2006. Analysis of flavonoids from propolis by online HPLC-electrospray mass spectrometry. J Pharm Biomed Anal 42: 354-361.

Watson DG, Peyfoon E, Zheng L, Lu D, Seidel V, Johnston B, Parkinson JA, Fearnley J. 2006. Application of principal components analysis to ${ }^{1} \mathrm{H}-\mathrm{NMR}$ data obtained from propolis samples of different geographical origin. Phytochem Anal 17: 323-331.

Zhang C-P, Zheng H-Q, Hu F-L. 2011. Extraction, partial characterization, and storage stability of $\beta$-glucosidase from propolis. J Food Sci 76: C75-C79. 